\title{
MJN \\ UNINTENDED PREGNANCY AND FAMILY PLANNING COUNSELING GUIDELINE ON MATERNITY NURSES' PERFORMANCE: CLINICAL BASED STUDY
}

\author{
Shymaa Abdel-Rahman Abdel-Haleem, Hadayat Abdel-Raoof Amasha*, Nagat Salah \\ Salama
}

\author{
Gynecology and Obstetrics Nursing, Faculty of Nursing, Port-Said University, Egypt \\ *Corresponding Author's Email: drtotoa67@yahoo.com
}

\begin{abstract}
Background: An unintended pregnancy is a substantial matter closely attached to public soundness, because of its adverse correlation with health outcome for both mothers and their own babies. Maternity nurses are responsible and play a key role in educating women on family planning to decline unintended pregnancy rate. The aim of the study was to design and implement a guideline for nurses regarding unintended pregnancy and family planning counseling. Subject and methods: Two research designs were used in the current study: A cross sectional design used to collect data about unintended pregnancy from women and a quasiexperimental design employed to assess the efficiency of the guideline regarding unintended pregnancy and family planning counseling among all on job nurses in family planning clinics in all MCH centers in Port Said. The data was collected using a structured interview schedule sheet for women and an observational checklist for nurses. Results: More than $30 \%$ of the studied women were exposed to unintended pregnancy and almost half of them did not use contraception. A statistically significant improvement was found in knowledge and practice of nurses in all tested elements about the unintended pregnancy and family planning counseling in the post-intervention $(P<0.001)$. Conclusion: The underlying reasons of unintended pregnancy were the use of no contraceptives and/or the failure of the method used for contraception. In addition, the implementation of a guideline on unintended pregnancy and family planning counseling has a positive effect on nurses' related knowledge and practices. Recommendations: It is recommended that the current guideline should be replicated in similar settings. Further research is recommended using different designs to evaluate the consequences of unintended pregnancy on pregnancy outcome.
\end{abstract}

Keywords: Unintended Pregnancy Nurses, Family Planning Counseling, Guideline

\section{INTRODUCTION}

It is worth mentioning that unintended pregnancy (UP) is a paramount public health matter in high, lowand middle-income countries because of its unfavorable correlation with the social and health outcomes for not only mothers but also children (WHO, 2015).

A study was carried out in Egypt to determine the prevalence of unintended pregnancy among married women. This study revealed that about one fifth of women reported unintended pregnancy. The Egyptian rate of unplanned pregnancy is closer to that noticed in Iran, where the rate was 35\% (Shaheen et al., 2007).

A study in Japan uncovered that $46.2 \%$ of the pregnancies were unexpected and more than two fifths of them have repeated experience of UP, the rate of which is still significantly considerable. Wrong or inconsistent use of contraceptives was frequently noted 
among participant in the greater proportion of UP especially in developed countries. None the less, in developing countries, the lack of access to contraceptive is the tacit reason (WHO, 2015).

Numerous studies have shown that unsatisfied needs of family planning (FP) can have significant ramifications for the health and well-being of women and children (Seyfried, 2011). Unmet need for contraception can lead to unintended pregnancies, with their harmful consequences such as unsafe abortions and unwanted births (Population Action International Healthy, 2011). Consequently, providing family planning services necessitates unparalleled skills, knowledge and sensibility to client needs (Bednash et al., 2009).

Ortayli \& Malarcher (2010), Creanga et al., (2011), Malarcher et al., (2011), Bongaarts et al., (2012) notified that miscellaneous social determinants can impact the demand for and use of FP, either personally or in several combinations such as literacy status, spousal communication, religion, women's autonomy, age, total children ever born, and age at first marriage. FP workers' visit and knowledge about FP are important to explain unintended pregnancy. In the multivariate analysis, these variables were found out to have statistically significant impact on unplanned pregnancy.

In addition, Hong et al., (2011) stated that the quality of family planning and venereal health services favorably impacts contraceptive use and behavior of the clients; and that clients should receive safe and high-quality services with reverence.

Clinical guidelines are intended is a guidance for both practitioners and patients to take decisions concerning the appropriate health care for given conditions. Therefore, the aim of this study is to design a guideline for nurses regarding unintended pregnancy and family planning counseling in Port Said.

\section{RESEARCH METHODOLOGY}

\section{Research Design}

\section{Two research designs were utilized in this study}

a- Cross sectional descriptive design was utilized for women to collect data about unintended pregnancy, contraceptives and factors influencing them.

b- Quasi-experimental research design (i.e. one group pre- and post-test) was employed for nurses to assess the effectiveness of the guideline regarding unintended pregnancy and family planning counseling.

\section{Study Setting}

To ensure generalization of the study results in Port Said City, the study was conducted in all hospitals and primary health care centers (i.e. antenatal and family planning clinics) representing the six districts of Port Said. Namely, primary health care centers (Bank ElEscan, El-Manakh (1), El manakh (2), El Kuwait, El arab (1), El Arab (2), Fatma El-Zahraa, Omar Ebn Elkhatab, El-Abouty, Osman Ebn Afan, Mostafa Kamel, Port Fouad (1), Port Fouad (2) and El-Gwhara) in addition to some hospitals (e.g. EL-Ameri Hospital (outpatient), ElNasr Hospital (outpatient), Port Fouad Hospital (outpatient), and El-Tadamon Hospital (outpatient).

\section{Study Population and Sample}

Two different samples were used. The first sample comprises women fulfilling the inclusion criteria. The second sample includes all nurses working in the above-mentioned hospitals.

\section{Inclusion criteria for women}

Women with at least one child and no medical or obstetric disorders and no previous contraindications for using FP methods were included in the current study.

\section{Sample size and type}

For women, a convenient sample of 600 women, attending the study setting and fulfilling the inclusion criteria, were registered in this study during study period (8 months). For nurses, a total coverage of 31 maternity nurses, working in the previously stated settings and willing to take part in the program, were enrolled for this study.

\section{Tools for data collection}

Two tools for data collection were used. The first tool was a structured interviewed schedule sheet for women. This tool was designed mainly to collect sociodemographic data, obstetrical history, history of current pregnancy, causes of unintended pregnancy, history of contraception; evaluation of women's needs to health education about contraceptive methods and their 
perception about nurse's role in family planning counseling. The second tool included a structured selfadministered schedule sheet and an observational checklist for nurses, which were used to evaluate nurses' knowledge and performance about unintended pregnancy and family planning counseling, (pre- and post-test). The ACQUIRE Project (2008) was used to collect data about counseling (RESPECT model) and counseling for contraceptive methods specifically to COCs and IUD. This training guide includes service provider's nonverbal communication, service provider's verbal communication, and RESPECT model process.

\section{Scoring system}

Concerning the knowledge items, a right response was scored 1 and the wrong one was scored zero. For each knowledge area, the scores of the items were summed up and the total of the scores was divided by the number of the items, providing the mean score for each part. These scores were converted into percentages, and the means and standard deviations were computed. Knowledge was regarded satisfying if the percentage was $60 \%$ or more and unsatisfactory if it is less than $60 \%$. The performance was regarded appropriate if the percent score was $60 \%$ or more and inadequate if it was less than $60 \%$.

\section{Operational design}

The study field was conducted through the following stages. The first phase is called preparation stage. It aimed at the preparation of the tools used in data collection based on a systematic review which concentrated on only one question seeking to identify, estimate, pick out and synthesize all high-quality research clues pertinent to that question. The tools were reviewed by a ten-expert jury majoring in obstetrics and gynecology to ascertain their content validity. Then, a guideline regarding unintended pregnancy and family planning counseling was prepared by the researcher based on past and recent related literature by using national and international references, and related journals, conferences and books. The program guideline was divided into theoretical and practical parts.

A pilot study was conducted over a period of two months. It was carried out on $10 \%$ of total sample size involving women and nurses to evaluate the content validity, time required to fill each tool and feasibility of tools of the study. Necessary modifications were carried out as revealed from the pilot study. The study tools were revised, redesigned and rewritten according to obtained results and acceptance of final forms. The fieldwork lasted for 8 months from the beginning of January 2015 to the end of August 2015.

In the assessment phase, the researcher interviewed women to find out if they were exposed to intended pregnancy or not and their contraceptive history. Women's need to health education regarding contraceptives and their perception about nurse's role in this regard was also included. A Structured interviewed schedule sheet was used.

For nurses, a self- administered schedule and an observation checklist were used to assess nurse's knowledge and performance (pre- and post-test).

\section{Planning phase: Guideline development}

A guideline was developed and submitted to the study group. It includes the following information: unintended pregnancy and how to reduce it, concept of family planning, benefits of family planning, and types of family planning methods and how to use it, family planning counseling, and protocols needed for practice in family planning clinics. The first phase deals with the process of developing a guideline in determining the clinical question that the guideline is expected to deal with. This is pursued by assigning the eligibility standards for the research studies comprised in the guideline recommendations. A systematic search of the previous analyses is then carried out. In developing recommendations, likely benefits, hazards, inconveniences and costs must be considered in addition to addressing patients' tacit values and predilections. The quality of the data enhancing the recommendations was examined and is reflected in a grading system describing the intensity of the recommendation and the quality of the backing clues.

\section{Implementation phase}

After the development of the guideline, the researcher started to give it for the intervention group of nurses. The guideline covered the theoretical and practical part of unintended pregnancy and family planning counseling and included definition of unintended pregnancy, reasons for unintended 
pregnancy, consequences of unintended pregnancy, measures for its prevention, the concept of family planning and its importance, different types of contraceptive methods, a guide to provide advice on the use of emergency, contraceptive method in case of unprotected intercourse and RESPECT model of counseling about contraceptive methods.

\section{Evaluation phase}

After the completion of implementation phase, the post-test was done after one week using the pre/posttest questionnaire to assess the nurse's knowledge and practice to find out the retention of the information given.

\section{Ethical considerations}

The study protocol was ratified by the pertinent committees at Port-Said University and written permissions to carry out the recent study were obtained from official authorities in the study setting. The researcher explained the aim of the study to each nurse and woman and their oral consent was taken, which was given after a brief explanation of the study to assure them that the data collected were clandestine and employed only for the sake of the study.

\section{Statistical analysis}

Statistical analysis was carried out utilizing SPSS version 16.0. Descriptive statistics were employed. In other words, frequencies and percentages were used for qualitative variables, whereas means and standard deviations were utilized for quantitative variables. As for quantitative continuous data, they were compared utilizing Student $t$-test in case of drawing comparisons between two groups. When the data were not normally distributed, the non-parametric Mann-Whitney test was employed instead. Further, the qualitative categorical variables were compared via chi-square test. When the expected values in one or more of the cells in a $2 \times 2$ tables was less than 5, Fisher exact test was employed instead. Moreover, in bigger than $2 \times 2$ cross-tables, no test was administered whenever the expected value was $10 \%$ or more of the cells were less than 5 . Statistical significance was checked at $p$-value $<0.05$.

\section{RESULTS}

According to socio-demographic peculiarities of the studied pregnant women, the ages of women ranged from 23-40 years, with a mean of 31.0 \pm 3.6 . Meanwhile, two thirds of them $(66.7 \%)$ were more than 30 years and $99.7 \%$ were married and $89.8 \%$ had urban residence, while $23.5 \%$ reported that they were employed at the time of the study. More than two thirds of the studied women $(67.2 \%)$ had secondary level of education and $20.2 \%$ could just read and write or had primary education. Meanwhile, more than one-half (63.2\%) reported that their monthly family income was not enough, and their mean crowding index was $2.3 \pm 0.3$.

Regarding prevalence and reasons of unintended pregnancy, figure 1 shows that about one third of the studied women $(31.3 \%)$ were exposed to unintended pregnancy and figure 2 shows the reasons given by women for the unintended pregnancy. It indicates that $44.0 \%$ didn't use contraceptives and partially similar proportion $(42.0 \%)$ experienced failure in the method used for contraception. The rest of them (14.0\%) reported that they discontinued using contraceptives before recent pregnancy.

Regarding prevalence and reasons of unintended pregnancy, figure 1 shows that about one third of the studied women $(31.3 \%)$ were exposed to unintended pregnancy and figure 2 shows the reasons given by women for the unintended pregnancy. It indicates that $44.0 \%$ didn't use contraceptives and partially similar proportion $(42.0 \%)$ experienced failure in the method used for contraception. The rest of them (14.0\%) reported that they discontinued using contraceptives before recent pregnancy.

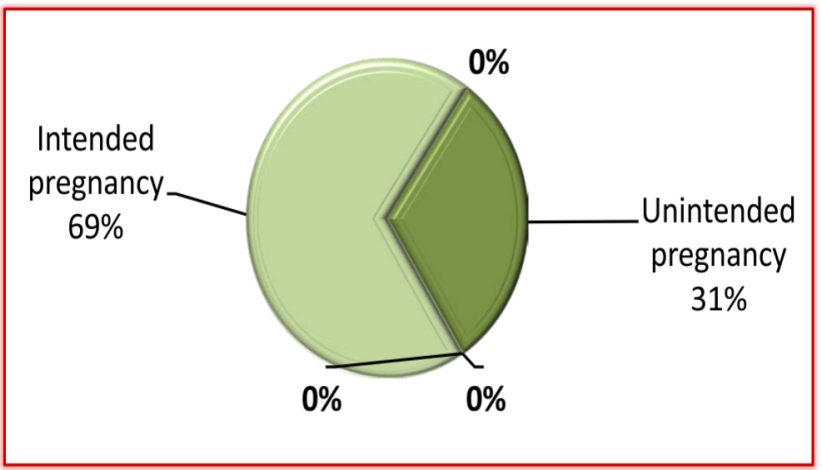

Figure 1: Distribution of the studied women according to their intention of pregnancy $(n=600)$ 


\section{Reasons for unintended pregnancy}

\section{Didn't use contraceptives}

- Failure of contraceptives

Discontinue using contraceptives before recent pregnancy

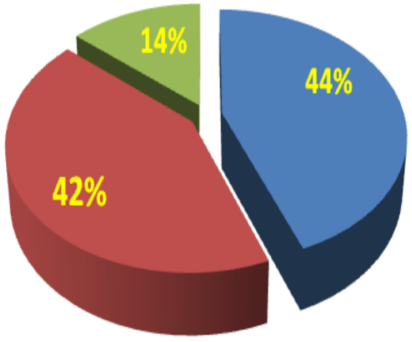

Figure 2: Reasons for unintended pregnancy $(n=188)$

It is obvious from table 1 that $13.8 \%$ of women exposed to unintended pregnancy were depressed and $30.9 \%$ were embarrassed and anxious about it. However, more than half of them (55.3\%) ignored this issue and did not think about. Only $13.8 \%$ of women had an attempt to abort the pregnancy using herbals $(61.3 \%)$, physical methods as jumping from high place $(22.6 \%)$ or taking drugs as misoprostol pills (16.1\%). But all of them failed to abort pregnancy.

Table 1: Response of Studied women toward unintended pregnancy $(n=188)$

\begin{tabular}{|l|l|l|}
\hline \multirow{2}{*}{ Items } & \multicolumn{2}{|l|}{ Women (n=188) } \\
\cline { 2 - 3 } & No. & \% \\
\hline \# Women response to the unintended pregnancy & \multicolumn{2}{|l}{} \\
\hline Being sad and feeling sorrow & 26 & 13.8 \\
Unhappy, embarrassed and anxious & 58 & 30.9 \\
Ignore this issue and does not think about it & 104 & 55.3 \\
\hline Attempt to abort the pregnancy & 26 & 13.8 \\
\hline "Methods used to abort pregnancy [n=26] & 19 & 61.3 \\
\hline Use herbals remedies & 7 & 22.6 \\
Jumping from high place & 5 & 16.1 \\
Using misoprestol pills & \multicolumn{2}{|l}{} \\
\hline
\end{tabular}

\# Categories are not mutually exclusive

As displayed in table 2, women with unplanned pregnancy were more likely to be older $(30-\leq 40)$ and married at an age more than 20 compared to those who had intended pregnancy $(77.7 \%$ vs. $61.7 \%$ and $88.8 \%$ vs. $74.8 \%$ respectively), differences observed are statistically significant $\left({ }^{F E} P=0.03 *\right)$. Meanwhile, they significantly apt to be housewives, had low level of education, and insufficient income $(88.8 \%$ vs. $70.9 \%$, $38.9 \%$ vs. $11.6 \%$ and $83.5 \%$ vs. $53.9 \%$ respectively).

Table 2: Relation between the intention of the current pregnancy and socio-demographic characteristics of the studied pregnant women $(n=600)$

\begin{tabular}{|c|c|c|c|c|c|}
\hline \multirow{3}{*}{$\begin{array}{l}\text { Socio-demographic } \\
\text { characteristics }\end{array}$} & \multicolumn{4}{|c|}{ Groups } & \multirow{3}{*}{ Significance } \\
\hline & \multicolumn{2}{|c|}{$\begin{array}{l}\text { Unintended } \\
(\mathrm{n}=188)\end{array}$} & \multicolumn{2}{|c|}{$\begin{array}{l}\text { Intended } \\
(\mathrm{n}=412)\end{array}$} & \\
\hline & No. & $\%$ & No. & $\%$ & \\
\hline \multicolumn{5}{|l|}{ Age (years) } & \multirow{3}{*}{$\begin{array}{l}X^{2}=14.888 \\
P<0.00001^{*}\end{array}$} \\
\hline $20-$ & 42 & 22.3 & 158 & 38.3 & \\
\hline $30-=40$ & 146 & 77.7 & 254 & 61.7 & \\
\hline \multicolumn{5}{|l|}{ Age at marriage } & \multirow{3}{*}{$\begin{array}{l}X^{2}=15.50 \\
P<0.0001^{*}\end{array}$} \\
\hline Less than 20 & 21 & 11.2 & 104 & 25.2 & \\
\hline More than 20 & 167 & 88.8 & 308 & 74.8 & \\
\hline \multicolumn{5}{|l|}{ Period of marriage } & \\
\hline Less than 10 & 94 & 50.0 & 217 & 52.7 & $X^{2}=0.369$ \\
\hline More than 10 & 94 & 50.0 & 195 & 47.3 & $P=0.544$ \\
\hline \multicolumn{5}{|l|}{ Residence } & \multirow{3}{*}{$\begin{array}{l}X^{2}=2.025 \\
P=0.155\end{array}$} \\
\hline Urban & 164 & 87.2 & 375 & 91.0 & \\
\hline Rural & 24 & 12.8 & 37 & 9.0 & \\
\hline \multicolumn{5}{|l|}{ Marital status } & \multirow{3}{*}{${ }^{\mathrm{FE}} P=0.03 *$} \\
\hline Married & 186 & 98.9 & 412 & 100.0 & \\
\hline Divorced & 2 & 1.1 & 0 & 0.0 & \\
\hline \multicolumn{5}{|l|}{ Occupation } & \multirow{3}{*}{$\begin{array}{l}X^{2}=23.152 \\
P<0.0001^{*}\end{array}$} \\
\hline Housewife & 167 & 88.8 & 292 & 70.9 & \\
\hline Working & 21 & 11.2 & 120 & 29.1 & \\
\hline \multicolumn{5}{|l|}{ Level of education } & \multirow{5}{*}{$\begin{array}{l}X^{2}=77.671 \\
{ }^{\mathrm{MC}} P=0.0001^{*}\end{array}$} \\
\hline can read and write & 8 & 4.3 & 1 & 0.2 & \\
\hline primary education & 65 & 34.6 & 47 & 11.4 & \\
\hline $\begin{array}{l}\text { Secondary } \\
\text { education }\end{array}$ & 111 & 59.0 & 292 & 70.9 & \\
\hline $\begin{array}{l}\text { University } \\
\text { education }\end{array}$ & 4 & 2.1 & 72 & 17.5 & \\
\hline \multicolumn{5}{|l|}{ Crowding index } & \multirow{3}{*}{$\begin{array}{l}Z=5.340 \\
P<0.0001^{*}\end{array}$} \\
\hline Min-Max & & & \\
\hline Mean \pm SD & \multicolumn{2}{|c|}{$2.4 \pm 0.3$} & \multicolumn{2}{|c|}{$\begin{array}{l}1.3-3.0 \\
2.2 \pm 0.3\end{array}$} & \\
\hline \multicolumn{5}{|l|}{ Monthly family income } & \multirow{3}{*}{$\begin{array}{l}X^{2}=48.703 \\
P<0.0001^{*}\end{array}$} \\
\hline Enough & 31 & 16.5 & 190 & 46.1 & \\
\hline Not enough & 157 & 83.5 & 222 & 53.9 & \\
\hline
\end{tabular}

As shown in table 3, unintended pregnant women were more likely to use contraceptive pills, for short period (less than one year), with improper counseling compared to those with intended pregnancy $(41.9 \%$ vs. $20.9 \%, 52.4 \%$ vs. $14.0 \%$ and $49.5 \%$ vs. $4.9 \%$ respectively). Meanwhile, they faced more side effects than the other group $(54.3 \%$ vs. $12.9 \%)$. Differences observed are statistically significant $P<0.0001 *$. 
Table 3: Relation between intention of the current pregnancy and use of contraceptives before recent pregnancy $(n=600)$

\begin{tabular}{|c|c|c|c|c|c|}
\hline \multirow{3}{*}{$\begin{array}{l}\text { Family planning methods } \\
\text { used }\end{array}$} & \multicolumn{2}{|c|}{ Groups } & & & \multirow{3}{*}{ Significance } \\
\hline & \multicolumn{2}{|c|}{$\begin{array}{l}\text { Unintended } \\
(\mathrm{n}=105)\end{array}$} & \multicolumn{2}{|c|}{$\begin{array}{l}\text { Intended } \\
(n=364)\end{array}$} & \\
\hline & No. & $\%$ & No. & $\%$ & \\
\hline $\begin{array}{l}\text { Type of family planning } \\
\text { used }\end{array}$ & & & & & \multirow{7}{*}{$\begin{array}{l}Z=2.036 \\
P=0.042^{*}\end{array}$} \\
\hline Condoms & 8 & 7.6 & 16 & 4.4 & \\
\hline $\begin{array}{l}\text { Pills (combined or } \\
\text { progesterone only) }\end{array}$ & 44 & 41.9 & 76 & 20.9 & \\
\hline Hormonal injection & 2 & 1.9 & 74 & 20.3 & \\
\hline IUD & 35 & 33.3 & 184 & 50.5 & \\
\hline Period safety & 2 & 1.9 & 5 & 1.4 & \\
\hline Lactational amenorrhea & 14 & 13.3 & 9 & 2.5 & \\
\hline \multicolumn{5}{|l|}{ Use based on counseling } & \multirow{3}{*}{$\begin{array}{l}X^{2}=57.594 \\
P<0.0001^{*}\end{array}$} \\
\hline Yes & 53 & 50.5 & 346 & 95.1 & \\
\hline Not & 52 & 49.5 & 18 & 4.9 & \\
\hline \multicolumn{5}{|l|}{ Duration of use } & \multirow{4}{*}{$\begin{array}{l}t=2.167 \\
P=0.037 *\end{array}$} \\
\hline One month & 2 & 1.9 & 1 & 0.3 & \\
\hline Less than a year & 55 & 52.4 & 51 & 14.0 & \\
\hline More than a year & 48 & 45.7 & 312 & 85.7 & \\
\hline \multicolumn{5}{|l|}{ Decision to use } & \multirow{4}{*}{$\begin{array}{l}Z=6.856 \\
P<0.0001^{*}\end{array}$} \\
\hline Husband only & 2 & 1.9 & 14 & 3.8 & \\
\hline Wife only & 76 & 72.4 & 111 & 30.5 & \\
\hline $\begin{array}{l}\text { A joint decision between } \\
\text { the spouse }\end{array}$ & 27 & 25.7 & 239 & 65.7 & \\
\hline \multicolumn{5}{|l|}{$\begin{array}{l}\text { Occurrence of side effects } \\
\text { after use the method }\end{array}$} & \multirow{3}{*}{${ }^{\text {мC }} P=0.001^{*}$} \\
\hline Yes & 57 & 54.3 & 47 & 12.9 & \\
\hline No & 48 & 45.7 & 317 & 87.1 & \\
\hline Side effects & \multicolumn{2}{|c|}{$(n=57)$} & \multicolumn{2}{|c|}{$(n=47)$} & \multirow{8}{*}{${ }_{P E}^{\mathrm{FE}}=0.024^{*}$} \\
\hline Bleeding between period & 34 & 50.0 & 24 & 51.1 & \\
\hline Increase in weight & 10 & 14.7 & 16 & 34.0 & \\
\hline Nausea & 4 & 5.9 & 0 & 0.0 & \\
\hline Chest pain & 7 & 10.3 & 4 & 8.5 & \\
\hline Headache & 3 & 4.4 & 3 & 6.4 & \\
\hline Mood swings & 5 & 7.4 & 0 & 0.0 & \\
\hline Severe pelvic pain & 5 & 7.4 & 3 & 6.4 & \\
\hline
\end{tabular}

$Z$ : Mann Whitney test $X^{2}$ :Chi-Square test ${ }^{M C} P$ : Monte Carlo test

${ }^{F E} P$ : Fisher's Exact test $t$ : $t$-test $*_{\text {significant at } P \leq 0.05}$

\#Categories are not mutually exclusive

The age of nurses ranged from 20 to 59 years, with a mean $38.4 \pm 8.1$ years. The great majority of nurses (96.8\%) were married, had nursing diploma and all of them attended training courses in family planning (table 4).
Table 4: Socio-demographic and academic characteristics of the studied nurses ( $n=31)$

\begin{tabular}{|c|c|c|}
\hline \multirow{2}{*}{ Socio-demographic characteristics } & \multicolumn{2}{|c|}{ Studied nurses } \\
\hline & No. & $\%$ \\
\hline \multicolumn{3}{|l|}{ Age (years) } \\
\hline $20-$ & 4 & 12.9 \\
\hline $30-$ & 15 & 48.4 \\
\hline $40-$ & 9 & 29.0 \\
\hline $50-<60$ & 3 & 9.7 \\
\hline Min-Max & \multicolumn{2}{|l|}{$25.0-59.0$} \\
\hline Mean $\pm S D$ & \multicolumn{2}{|l|}{$38.4 \pm 8.1$} \\
\hline \multicolumn{3}{|l|}{ Marital status } \\
\hline Married & 30 & 96.8 \\
\hline Widowed & 1 & 3.2 \\
\hline \multicolumn{3}{|l|}{ Educational level } \\
\hline Nursing diploma & 30 & 96.8 \\
\hline Nursing institute & 1 & 3.2 \\
\hline \multicolumn{3}{|c|}{ Duration of nursing experience in Family planning (years) } \\
\hline $1-$ & 14 & 45.2 \\
\hline $10-$ & 13 & 41.9 \\
\hline $20-<30$ & 4 & 12.9 \\
\hline Min-Max & \multicolumn{2}{|l|}{$1.0-25.0$} \\
\hline$M e a n \pm S D$ & \multicolumn{2}{|l|}{$9.5 \pm 5.7$} \\
\hline \multicolumn{3}{|l|}{ Received training on family planning } \\
\hline No & 0 & 00.0 \\
\hline Yes & 31 & 100 \\
\hline
\end{tabular}

Table 5 demonstrates statistically significant improvement in nurses' knowledge about the unintended pregnancy post-intervention in all tested elements. In total, $64.5 .0 \%$ of nurses had satisfying knowledge at the pre- intervention stage, and this augmented to $90.3 \%$ at the post-test $(p<0.001)$. The same table indicates that nurses in the post-test had statistically significant increase $(p<0.001)$ in their total knowledge of COCs. It was particularly evident regarding the side effects of COCs and the follow up visits $(100.0 \%$ vs. $71.0 \%$, and 100.0 vs. $90.3 \%$ respectively) followed by the indications and contraindications of COCs and $(96.8 \%$ vs. $61.3 \%$ and $93.5 \%$ vs. $32.5 \%$ respectively). 
Table 5: Distribution of nurses according to satisfactory knowledge throughout the study phases (n=31)

\begin{tabular}{|c|c|c|c|c|c|}
\hline \multirow{3}{*}{ Areas of knowledge } & \multicolumn{4}{|c|}{ Satisfactory knowledge of nurses } & \multirow{3}{*}{\begin{tabular}{|l|}
$\begin{array}{l}\text { Paired } t \text {-test } \\
(P \text { value })\end{array}$ \\
$P$ value \\
\end{tabular}} \\
\hline & \multicolumn{2}{|c|}{ Pre intervention } & \multicolumn{2}{|c|}{ Post intervention } & \\
\hline & No. & $\%$ & No. & $\%$ & \\
\hline \multicolumn{6}{|l|}{ Knowledge about unintended pregnancy (UP) } \\
\hline Definition of UP & 31 & 100.0 & 31 & 100.0 & -NA- \\
\hline Causes of UP & 20 & 64.5 & 26 & 83.9 & $<0.001^{*}$ \\
\hline Adverse effects of UP & 11 & 35.5 & 25 & 80.6 & $<0.0001 *$ \\
\hline Followed Guidelines to reduce UP rate & 17 & 54.8 & 29 & 93.5 & $<0.0001^{*}$ \\
\hline Total score & 20 & 64.5 & 28 & 90.3 & $<0.001^{*}$ \\
\hline \multicolumn{6}{|l|}{ Knowledge about Compound Contraceptive methods (COCs) } \\
\hline Effectiveness of COCs & 17 & 54.8 & 24 & 77.4 & $<0.0001^{*}$ \\
\hline Rumors and misconception about & 10 & 32.3 & 29 & 93.5 & $<0.0001^{*}$ \\
\hline Criteria of selecting women & 19 & 61.3 & 30 & 96.8 & $<0.002 *$ \\
\hline Known medical conditions that contradicting use & 22 & 71.0 & 28 & 90.3 & $<0.001^{*}$ \\
\hline Side effects of COCs & 22 & 71.0 & 31 & 100.0 & $<0.0001^{*}$ \\
\hline Warning signs \& possible complications & 10 & 32.3 & 24 & 77.4 & $<0.0001 *$ \\
\hline Appropriate follow-up schedule after using COCs & 28 & 90.3 & 31 & 100.0 & 0.25 \\
\hline Timing and reasons for stoppage of $\mathrm{COCs}$ & 18 & 58.1 & 23 & 74.2 & $<0.0003 *$ \\
\hline Total score & 18 & 58.1 & 28 & 90.3 & $<0.0001^{*}$ \\
\hline \multicolumn{6}{|l|}{ Knowledge about Intra Uterine Devise (IUD) } \\
\hline Effectiveness of IUD & 18 & 58.1 & 28 & 90.3 & $<0.0001 *$ \\
\hline Rumors and misconception about method \&how to clear it up & 11 & 35.5 & 18 & 58.1 & $<0.004^{*}$ \\
\hline Criteria of selecting women & 10 & 32.2 & 27 & 87.1 & $<0.0001^{*}$ \\
\hline Known medical conditions that contradicting use & 22 & 71.0 & 27 & 87.1 & $<0.001^{*}$ \\
\hline Side effects of IUD & 15 & 48.4 & 26 & 83.9 & $<0.0001^{*}$ \\
\hline Warning signs of possible complications & 16 & 51.6 & 26 & 83.9 & $<0.0001^{*}$ \\
\hline Appropriate follow-up schedule after insertion IUD & 16 & 51.6 & 25 & 80.6 & $<0.0001^{*}$ \\
\hline Timing and reasons for stoppage of IUD & 23 & 74.2 & 27 & 87.1 & 0.125 \\
\hline Total score & 16 & 51.6 & 26 & 83.9 & $<0.0001 *$ \\
\hline
\end{tabular}

*significant at $P \leq 0.05$

Regarding knowledge of nurses about IUD, almost half $(51.6 \%)$ of nurses acquired satisfying knowledge before the intervention of the program; and this augmented to $83.9 \%$ at the intervention $(p<0.001)$. As for nurses' knowledge about IUD, statistically significant improvement was observed in all tested variables $(p<0.001)$. In total, improvement was more marked in the effectiveness of the IUD, its indications, contraindications and danger signs. However, slight change was noticed regarding rumors and misconception concerning IUD and the methods of clearing them up $(58.1 \%$ vs. $35.5 \%)$.

Table 6 describes the Six-Step Counseling Model (i.e. RESPECT). These forces were included in this model and they weigh heavily in accepting or rejecting 
family planning methods, in addition to continuous compliance that are mentioned by Pathfinder and WHO (2008) and used by the researchers to train nurses about. It revealed that after implementing of the program, most nurses were significantly more likely to use verbal or non-verbal communication and RESPECT parameters when counseling. The difference observed is statistically significant $(P<0.0001)$.

Table 6: Observational checklist about counseling skills (RESPECT model) practiced by the studied nurses throughout the study phases

\begin{tabular}{|c|c|c|c|c|c|}
\hline \multirow{3}{*}{ Tasks } & \multicolumn{4}{|c|}{ Studied nurses $(\mathrm{n}=\mathbf{3 1})$} & \multirow{3}{*}{$\begin{array}{l}\begin{array}{l}\text { Paired } t \text { - test } \\
\text { (P value) }\end{array} \\
p \text {-value }\end{array}$} \\
\hline & \multicolumn{2}{|c|}{$\begin{array}{l}\text { Pre- } \\
\text { intervention }\end{array}$} & \multicolumn{2}{|c|}{$\begin{array}{l}\text { Post } \\
\text { intervention }\end{array}$} & \\
\hline & No. & $\%$ & No. & $\%$ & \\
\hline $\begin{array}{l}\text { Using non-verbal } \\
\text { communication }\end{array}$ & 11 & 35.5 & 27 & 87.1 & $<0.0001^{*}$ \\
\hline $\begin{array}{l}\text { Using verbal } \\
\text { communication }\end{array}$ & 10 & 32.2 & 27 & 87.1 & $<0.0001 *$ \\
\hline \multicolumn{6}{|c|}{ Practicing RESPECT model process } \\
\hline Rapport & 20 & 64.5 & 26 & 83.9 & $<0.002^{*}$ \\
\hline Empathy & 13 & 41.9 & 24 & 77.4 & $<0.0001^{*}$ \\
\hline Support & 17 & 54.8 & 28 & 90.3 & $<0.0001^{*}$ \\
\hline Partnership & 19 & 61.3 & 24 & 77.4 & $<0.006^{*}$ \\
\hline Explanations & 15 & 48.4 & 25 & 80.6 & $<0.0001^{*}$ \\
\hline Cultural Sensitivity & 25 & 80.6 & 25 & 80.6 & -NA- \\
\hline Trust & 12 & 38.7 & 28 & 90.3 & $<0.0001^{*}$ \\
\hline Total score & 17 & 55.7 & 26 & 82.9 & $<0.0001 *$ \\
\hline
\end{tabular}

*significant at $p \leq 0.05$

\section{DISCUSSION}

Unmet need for contraceptive methods can lead to unintended pregnancies, with their adverse consequences for mothers and their babies such as unsafe abortions and unwanted births.

According to the findings of the current study, about one third of the studied women were exposed to unintended pregnancy. This is in coherence with El zanaty et al., (2001) in Egypt, Kiersten, Zoubi \& Wulfe, (2004) in Jordon, Shaheen et al., (2007) in Islamic Republic of Iran, and Hamadela \& Tizta, (2012) in Ethiopia, where the rate was $35.0 \%$. But a lower extent i.e. one fifth of all the births were detailed by Jaeni et al., (2009) in Indonesia, Faye et al., (2013) in Senegal $(14.3 \%)$ and Sedgh et al., (2014) in Nigeria (28.0\%). Besides, a higher number of women experiencing unintended pregnancy were reported by nearly half of women Adhikari et al., (2009) in Nepal and 54.1\% in Tanzania (Exavery et al., 2014). The disparities among the various studies addressing the above-mentioned prevalence and the present one has been attributed to diverse tradition, cultural and religious denominations between different nation.

On exploring women's response to the unintended pregnancy, less than one fifth was sad and felt sorrow. Nevertheless, more than half of them ignored this issue and does not think about it. This may be attributed to Muslims' religious belief which considers pregnancy as God's blessing or treasure of the family. Meanwhile, many studies have attached unplanned pregnancy and childbearing to disquiet, guilt, blame and other psychosocial circumstances (Gipson et al., 2008; Weitz Kimport, 2012). Recently, Jalay et al. (2015), Gerdts et al.,(2016) showed that unplanned pregnancies are more probably to result in unfavorable well being conduct.

Oral contraceptives are the most popular form of reversible contraception and one million accidental pregnancies occur each year related to their use, misapplication, or discontinuation. In addition, new users of oral contraceptives are more likely to stop using them within the first year, mostly because of its side effects. The results of the recent study uncovered that most of the studied women become pregnant because of either contraceptive failure or stopped using contraceptive methods, slightly less than half using oral contraceptive on their own and not based on counseling, the wife only decided to use family planning and slightly more than half of them experienced side effect after using contraception such as bleeding between period, increase in weight and chest pain. This finding is in accordance with Bradley et al. (2011).

Speidel, Harper \& Shields, (2008) stated that unintended pregnancies are the most obvious reason for induced abortions, resulting in about 42 million induced abortions all over the world. But Urassa et al., (2008)'s study in Tanzania reported that $88.0 \%$ of 
unwanted pregnancies ended up into abortion, of those $26.0 \%$ were induced rather than being spontaneous. In this regard, Guttmacher Institute (2010) asserted that unplanned birth rate was 22 per 1,000 for women aged 15-44 and the abortion rate was 17 per 1,000 women. On exploring women's reaction in the current study, approximately less than one fifth of unintended pregnant women had an endeavor to end pregnancy (abort pregnancy), but they all fizzled to abort. This may be due to that in Egypt, induced abortion is generally undocumented because of religious and legislative denial and disgrace.

From the present finding it is evident that the factors impacting the occurrence of unintended pregnancy, included socio-demographic and access to family planning health information/services. The analysis showed that the factors such as education status and women's autonomy along with the procedures of family planning are imperative to clarify accidental pregnancy. In the multivariate analysis, these variables were found out to have statistically significant impact on unplanned pregnancy. These findings are partially in congruence with Ortayli \& Malarcher (2010), Creanga et al., (2011), Malarcher et al., (2011) and Bongaarts et al., (2012). They reported that several social determinants can affect the demand for and use of family planning, either individually or in various combinations.

There are numerous studies that uphold the significance of understanding the most effective factors that locate the demand and use in a particular place, and, in turn, for defining those populations which are underserved and have the most noticeable neglected requirements (Cleland et al., 2006; DFID, 2010). The extent to which public determinants interact and affect demand for, access to, and use of family planning services, and thus augmenting inequities, is excessively contextual and population-based. Situation-given analyses should consequently be assumed to generate clues for guiding rights-based program development in all countries (Ortayli \& Malarcher, 2010).

A number of studies have shown that there is relationship between age of the woman and increased risk of accidental pregnancy. The results of this study show that women with unplanned pregnancy were more likely to be older $(30-\leq 40)$. This is partially in agreement with Adhikari et al., (2009) from Nepal, Jaeni et al., (2009) from Indonesia, Najafian et al., (2010) from Iran, and Geda \& Lako (2012) from Nigeria. These findings are in accordance with studies conducted in Ecuador, Vietnam, China, and Bangladesh among pregnant women in reproductive age group. These studies reported that as women's age advances, the likelihood of unplanned pregnancy boosts (Calverton, 2014).

The present study shows that women with unintended pregnancy were married at an age more than 20 compared to those who had intended pregnancy. This may be due to the delayed age of marriage in Egypt. Unlikely, Nasab et al., (2010) in Iran found that women married before the age of 18 were 4.6 times more probably to undergo unplanned pregnancy compared to those who were married at age of 18 and above. Also, Nasab et al., (2010) found that the rate of unplanned pregnancy significantly augmented in the age group less than 18 when being compared to those married between 19-24 years.

Regarding education status, the finding of the present study shows that nearly half of the unintended pregnant women had low level of education. This is supported by Finer \& Zolna (2014) in United States who reported that women with no high school degrees attained the highest unplanned pregnancy rate among all educational levels (73 women per 1,000 women aged between 15 and 44), and rates were lower for those with more years of education. In contrast, Stephenson et al., (2008) noticed that women who attained primary, secondary and higher education were more probably to report accidental pregnancy when being compared to ladies with no education. Such dissimilarities among the results of the above-mentioned studies and the present one could be related to the differences in the sample size and its criteria of selection.

More than three quarters of the unintended pregnant women in this study were housewives and had an insufficient income. This is partially in accordance with Finer \& Zolna (2014). Conversely, Exavery et al., (2014) in Tanzania, found out that women occupation was not significantly related to unintended pregnancy. This dissimilarity between the various studies may be related to the difference in the setting or in the measurement of the socio-economic variable. Several studies measure this variable after construing the proxy variables of socio-economic status. It is worth mentioning that very few studies measure this variable by posing questions concerning the income of the household categories of this variable (e.g. poor, middle 
and rich) arbitrary. Consequently, the results need to be interpreted carefully (Exavery et al., 2014; Mukaba et al., 2015).

Nurses' ages ranged from 20 to 59 years with a mean age of $38.4 \pm 8.1$ with the highest percentage were between $30-<40$ years and most of the nurses had nursing diploma and were married. Nearly half of nurses had an experience that ranged between $1-<10$ years of experience with a mean of $9.5 \pm 5.7$ years. In this regard, Clawson \& Haskins (2006) commented that there is evidence stating that the more experienced nurse is capable of understanding the complexities of clinical situation rapidly and can differentiate between pertinent and insignificant data.

The finding of the current study has shown that despite the fact that all nurses were aware of the unintended pregnancy and family planning counseling, their baseline knowledge about it was not satisfied. Thus, at the pre-planning phase of the guideline, none of the them had a satisfactory knowledge about unintended pregnancy and family planning counseling which include rumors and misconception about method and how to clear it up, criteria of selecting women, warning signs of possible complications, the reasons for seeking medical advice, and appropriate family planning followup schedule.

Previous studies have examined the influence of official training programs on nurses' ability to liaise with patients. The results that such training programs can improve the quality of family planning counseling significantly and other types of nurse-patient liaison such as active listening, friendship, body gestures and compliment also help regarding this matter (Shattell, 2004; Kim et al., 2008).

The findings of the present study revealed a significant improvement in the post-test of nurse's knowledge and practice regarding unintended pregnancy and family planning counseling. This result was in harmony with Lamiani \& Furey (2008), whose findings showed that a 2-day workshop on patient education, based on a patient-centered method, ameliorate nurses' communication skills and knowledge, and their sense of readiness. Furthermore, they reported that patient handling skills can be easily taught and learned the same as other nursing skills. Nurses must be provided with more educational chances based on a patient-centered technique to brush up their patient related education skills.

The foregoing findings confirm the positive effect of the evidence-based guideline in improving the counseling knowledge and practice of nurses regarding family planning and unintended pregnancy. This may be ascribed to the reality that the researchers utilized straightforward applications and role playing in order to simplify the information and help nurses to apply their knowledge to practice.

\section{CONCLUSION AND RECOMMENDATION}

The findings of the study concluded that unplanned pregnancies can result in insecure abortion, which may have adverse consequences for the mother. Most accidental pregnancies can be prevented via minimizing unsatisfied needs for efficient, convenient, contraceptive ways. This can be carried out via concentrating on the information given by nurses to the recently wed couples and gravid ladies during prenatal check-ups. Based on these results, training programs are recommended for nurses to enhance their knowledge and skills regarding unintended pregnancy and different kinds of contraceptives so that they can educate and counsel women. Antenatal and postnatal counseling programs for women using simple illustrative booklets and pamphlets in Arabic language can be used to reduce the unmet need within the country. Finally, replication of the present study at different setting and among various subjects is recommended. Meanwhile, further research is recommended about other pre-determinants of unintended pregnancy and its consequences on both mother and baby.

\section{Limitation of the study}

As for the limitation of the study, it was not easy to round up all the nurses together at the same time due to their working circumstances. This was considered and arranged during the implementation of the study. Moreover, the researcher faced difficulties to select the purposive sample of women keeping in mind the inclusion criteria and short period allocated for the study. Thus, the program was limited to the two mentioned methods (IUD, COCs).

\section{Conflict of Interest}

The authors declare no conflict of interest 


\section{REFERENCES}

Adhikari, R., Soonthorndhada, K. \& Prasartkul, P. (2009). Correlates of unintended pregnancy among currently pregnant married women in Nepal. BMC International Health and Human Rights, 9(1), pp 17.

Bednash, G., Worthington, S. \& Wysocki, S. (2009). Nurse practitioner education: keeping the academic pipeline open to meet family planning needs in the United States. Contraception, 80(5), pp 409-411.

Bongaarts, J.J., Cleland, J., Townsend, J.W. Bertrand, J.T. \& Gupta, M.D. (2012). Family Planning Programs for the $21^{\text {st }}$ Century. Rationale and Design. New York: The Population Council, Inc.

Bradley, S.E.K., Croft, T.N. \& Rutstein, S.O. (2011). The impact of contraceptive failure on unintended births and induced abortions: Estimates and strategies for reduction. DHS Analytical Studies No. 22. Calverton, Maryland, USA: ICF Macro. Retrieved from: http://dhsprogram.com/pubs/pdf/AS22/AS22.pdf.

Calverton, M.U. (2014). Demographic and health survey. National institute of population studies Islamabad, Pakistan 2012-2013. Calverton: Macro International Inc.

Clawson, J. \& Haskins, M. (2006). Teaching management: a field guide for professors, corporate trainers and consultants. Cambridge University Press, UK.

Cleland, J., Bernstein, S., Ezeh, A., Faundes, A., Glasier, A. \& Innis, J. (2006). Family planning: the unfinished agenda. The Lancet, 368(9549), pp1810-27.

Creanga, A.A., Gillespie, D., Karklinsa, S. \& Tsui, A.O. (2011). Low use of contraception among poor women in Africa: An equity issue. Bulletin of World Health Organ, 89(4), pp 258-266.

Department for International Development (DFID) (2010). Improving Reproductive, Maternal and Newborn Health: Burden, Determinants and Health Systems. Evidence Overview. Working Paper(Version 1.0). London, UK: DFID.

El-Zanaty, F. \& Way, A. (2001). Egypt demographic and health survey 2000. Calverton, Maryland [USA], Ministry of Health and Population [Egypt], National Population Council and ORC Macro.

Exavery A., Kante A.M., Njozi M., Tani K., Doctor H.V., Hingora A. \& Phillips, J.F. (2014). Predictors of mistimed, and unwanted pregnancies among women of childbearing age in Rufiji, Kilombero, and Ulanga districts of Tanzania. Reproductive Health, 11:63.

Faye, C.M., Speizer, I.S., Fotso, J.C., Corroon, M. \& Koumtingue, D. (2013). Unintended pregnancy: magnitude and correlates in six urban sites in Senegal. Reproductive Health, 10(1), 59.

Finer, L.B. \& Zolna, M.R. (2014). Shifts in intended and unintended pregnancies in the United States, 2001-2008. American Journal of Public Health. 104 Suppl 1, S43-8.

Geda, N.R. \& Lako, T.K.A. (2011). Population based study on Unintended Pregnancy among Married Women in a District in Southern Ethiopia. Journal of Geography and Regional Planning, 4(7), pp 417-27.

Gerdts C., Dobkin, L., Foster, D.G. \& Schwarz, E.B. (2016). Side effects, physical health consequences, and mortality associated with abortion and birth after an unwanted pregnancy. Women s Health Issues, 26(1), pp 55-59.

Gipson, J.D., Koenig, M.A. \& Hindin, M.J. (2008). The effects of unintended pregnancy on infant, child, and parental health: A review of the literature. Studies in Family Planning, 39(1), pp 18-38.

Guttmacher Institute (2018). Fact Sheet: Induced abortion in the United States. Retrieved from: https://www.guttmacher.org/sites/default/files/factsheet/fb_induced_abortion.pdf

Hamadela, B. \& Tizta, T. (2012). Unwanted pregnancy and associated factors among pregnant married women in 
Hosanna Town, Southern Ethiopia. PLoS One, 7.6: e39074.

Hong, R., Mishra, V. \& Fronczak N. (2011). Impact of a quality improvement programme on family planning services in Egypt. Eastern Mediterranean Health Journal, 17(1), pp 4-10.

Jaeni, N., McDonald, P. \& Utomo, I.D. (2009). Determinants of Unintended Pregnancy among Ever-Married Women in Indonesia: An Analysis of the 2007 IDHS. Australian Demographic and Social Research Institute.

Jalaly P., Ghodsi Z., Simin Hojjatoleslami (2015). Health Behavior's Deference in Intended and Unintended Pregnancies. Procedia-Social and Behavioral Sciences, 185, pp 156-159.

Kiersten, J., Zoubi, O. \& Wulfe, M (2004). Mistimed and Unwanted Pregnancies in Jordan. Calverton, Maryland, USA: Jordan Department of Statistics and ORC Macro.

Kim, Y., Heerey, M. \& Kols, A. (2008). Factors that enable nurse-patient communication in a family planning context: A positive deviance study. International Journal of Nursing Studies, 45(10), pp 1411-1421.

Lamiani, G. \& Furey, A. (2008). Teaching nurses how to teach: An evaluation of a workshop on patient education. Patient Education Counseling, 75(2), pp 270-273.

Malarcher, S., Meirik, O., Lebetkin, E., Shah, I., Spieler, J. \& Stanback, J. (2011). Provision of DMPA by community health workers: What the evidence shows. Contraception, 83(6), pp 495-503.

Mukaba T., Binanga, A., Fohl, S. \& Bertrandc, J.T. (2015). Family planning policy environment in the Democratic Republic of the Congo: levers of positive change and prospects for sustainability. Global Health: Science and Practice; 3(2), pp 163-173.

Najafian, M., Karami, K.B., Cheraghi, M. \& Jafari, R.M. (2010). Prevalence of and Some Factors Relating with Unwanted Pregnancy, in Ahwaz City, Iran. ISRN Obstetrics and Gynecology, vol. 2011, Article ID 523430; 1- 4.

Nasab, H.S., Tavakoli, R., Tavakoli, H., Jahan, H.R. \& Shkravi F.A. (2010). Unwanted Pregnancy and Factors Influencing it in Pregnant Mothers Referring to Semnan's Health Centers. World Applied Sciences Journal, 9(2), pp199-203.

Ortayli, N. \& Malarcher, S. (2010). Equity analysis: Identifying who benefits from family planning programs. Studies in Family Planning, 41(2), pp 101-108.

Population Action International Healthy (PAI) (2011). Why Population Matter to Maternal Health. Washington: Population Action International Healthy Family Healthy Planet.

Sedgh G., Singh S. \& Hussain, R. (2014). Intended and unintended pregnancies worldwide in 2012 and recent trends. Studies in Family Planning, 45(3), pp 301-314.

Seyfried, L. (2011). Family Planning and Maternal Health, The Effect of Family Planning and Maternal Health in the Democratic Republic of Congo. Published Master Thesis, Faculty of Georgetown University, Washington, DC.

Shaheen, A.A., Diaaeldin, M., Chaaya, M. \& El Roueiheb, Z. (2007). Unintended pregnancy in Egypt: evidence from the national study on women giving birth in 1999. Eastern Mediterranean Health Journal, 13(6), pp 1392 $-1404$.

Shattell, M. (2004). Nurse-patient interaction: a review of the literature. Journal of Clinical Nursing, 13(6), pp 71422.

Speidel, J.J., Harper, C.C. \& Shields, W.C. (2008). The Potential of Long-acting Reversible Contraception to Decrease Unintended Pregnancy. Contraception, 78(3), pp 197-200.

Stephenson, R., Koenig, M.A., Acharya, R. \& Roy, T.K. (2008). Domestic violence, contraceptive use, and 
unwanted pregnancy in rural India. Studies in Family Planning, 39(3), pp 177-186.

The ACQUIRE Project (2008). Programming for training: A resource package for trainers, program managers, and supervisors of Reproductive Health and Family Planning Programs. New York: Engender Health/The ACQUIRE Project.

Urassa, W., Moshiro, C., Chalamila, G., Mhalu, F. \& Sandstorm, E. (2008). Risky Sexual Practices among Youth Attending a Sexually Transmitted Infection Clinic in Dar es Salaam. Tanzania. BMC Infectious Diseases, 8, pp 159.

Weitz, T.A. \& Kimport, K. (2012). A need to expand our thinking about "repeat" abortions. Contraception, 85(4), pp 408-412.

World Health Organization (2015). Why do so many women still die in pregnancy or childbirth? Retrieved from: https://www.who.int/features/qa/12/en/ 